Check for updates

Cite this: RSC Adv., 2021, 11, 11606

Received 3rd February 2021

Accepted 11th March 2021

DOI: 10.1039/d1ra00915j

rsc.li/rsc-advances

\section{Catalytic enantioselective intramolecular Tishchenko reaction of meso-dialdehyde: synthesis of $(S)$-cedarmycins $\uparrow$}

\author{
Ismiyarto, ${ }^{a}$ Nobuki Kishi, ${ }^{\text {b }}$ Yuki Adachi, ${ }^{a}$ Rui Jiang, ${ }^{a}$ Takahiro Doi, ${ }^{a}$ Da-Yang Zhou, ${ }^{a}$ \\ Kaori Asano, ${ }^{a}$ Yasushi Obora, (D) b Takayoshi Suzuki, ${ }^{a}$ Hiroaki Sasai ${ }^{a}$ \\ and Takeyuki Suzuki iD *a
}

The first successful example of a catalytic enantioselective intramolecular Tishchenko reaction of a mesodialdehyde in the presence of a chiral iridium complex is described. Chiral lactones were obtained in good yields with up to $91 \%$ ee. The obtained enantioenriched lactones were utilized for the first synthesis of (S)cedarmycins $\mathrm{A}$ and $\mathrm{B}$.
The catalytic dimerization of aldehydes giving the corresponding esters was first discovered by Claisen in $1887,{ }^{1}$ and is now well known as the "Tishchenko reaction" (Scheme 1).

Claisen's method utilizing sodium alkoxides, however, could only be applied to nonenolizable aldehydes like benzaldehyde, because enolizable aldehydes undergo aldol reactions when treated with strong bases such as sodium alkoxides. ${ }^{1}$ In 1906 , a Russian chemist, Tishchenko, reported that aluminum alkoxides were superior to sodium alkoxides in the reaction, because they were more Lewis acidic and less basic. ${ }^{2}$ The transformation of acetaldehyde into ethyl acetate is the representative application of the Tishchenko reaction in the chemical industry. ${ }^{3}$ So far, a number of homogeneous catalysts exhibiting high catalytic performance for the Tishchenko reaction have been developed to compensate for the drawback of the classical aluminum alkoxide catalysts. ${ }^{4}$ In 2005 , we reported a mild Tishchenko dimerization using a Ir catalyst. ${ }^{5}$ The reaction proceeds at room temperature and is effective with a wide range of aldehydes. We also reported the enantioselective oxidative lactonization ${ }^{6}$ of meso-diols for the preparation of

$$
2 \mathrm{RCHO} \stackrel{\text { catalyst }}{\longrightarrow}
$$

Scheme 1 Tishchenko reaction.

${ }^{a}$ The Institute of Scientific and Industrial Research, Osaka University, Mihogaoka, Ibaraki, Osaka 567-0047, Japan. E-mail: suzuki-t@sanken.osaka-u.ac.jp

${ }^{b}$ Department of Chemistry and Materials Engineering, Faculty of Chemistry, Materials, and Bioengineering, Kansai University, Suita, Osaka 564-8680, Japan

$\dagger$ Electronic supplementary information (ESI) available: Experimental details, compond characterization, NMR and CSI spectra. CCDC 2019330 (9) and 2022569 (11). For ESI and crystallographic data in CIF or other electronic format see DOI: 10.1039/d1ra00915j chiral lactones. ${ }^{7}$ Although asymmetric aldol-Tishchenko reactions $^{8}$ for chiral 1,3-diols are known, there is no report of an asymmetric intramolecular Tishchenko reaction of meso-dialdehydes for chiral lactones. We envisaged that the asymmetric borrowing hydrogen methodology ${ }^{9}$ could be applied to achieve an enantioselective intramolecular Tishchenko reaction of meso-dialdehydes (Scheme 2).

The initial enantioselective reduction of meso-dialdehyde 1 could occur by a chiral 18 electron Ir hydride complex to afford chiral hydroxy aldehyde 2 . The hydroxy aldehyde-lactol equilibrium would generate lactol 3. Finally, irreversible oxidation of 3 would produce the desired lactone 4 .

With this hypothesis in mind, we began the investigation of the intramolecular Tishchenko reaction using $o$-phthalaldehyde

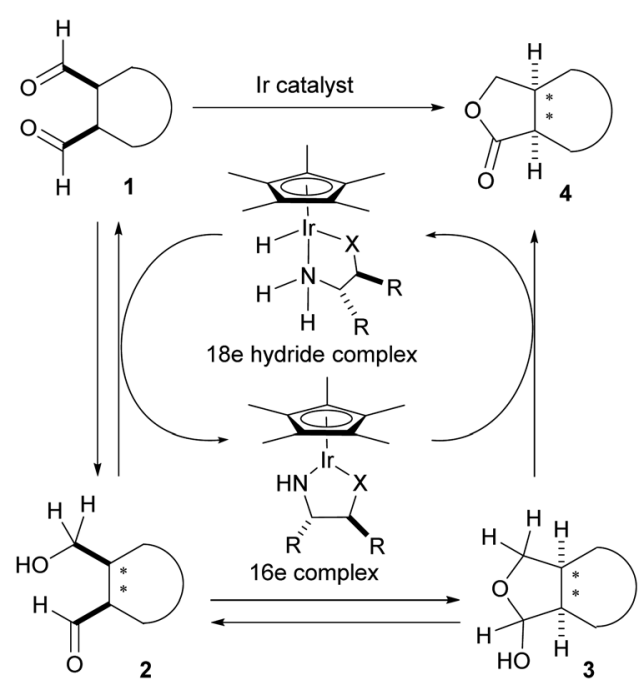

Scheme 2 Strategies for enantioselective intramolecular Tishchenko reaction. 
as a model substrate (Table 1). When a mixture of $o$-phthalaldehyde (6a) in $\mathrm{CH}_{2} \mathrm{Cl}_{2}$ containing the Ir complex 5a, ${ }^{10}{ }^{i} \mathrm{PrOH}$, and $\mathrm{K}_{2} \mathrm{CO}_{3}$ (6a : 5a: ${ }^{i} \mathrm{PrOH}: \mathrm{K}_{2} \mathrm{CO}_{3}=100: 1: 20: 20 \mathrm{~mol}$ ratio) was stirred at $30{ }^{\circ} \mathrm{C}$ for $7 \mathrm{~h}$, lactone (7a) was obtained in $97 \%$ yield (entry 1). The reaction did not proceed at all in the absence of Ir catalyst (entry 2). Interestingly, the reaction without the additional hydrogen donor, ${ }^{i} \mathrm{PrOH}$, also gave the lactone, but the yield was low (entry 3). To enhance the reactivity, the addition of a base was necessary. ${ }^{5 a}$ Without base or with a lower amount of base, the reaction proceeded in less than $28 \%$ yield (entries 4,5). The reaction of 2,3-naphthalene dicarboxaldehyde 6b also proceeded similarly under optimized conditions (entry 6).

Encouraged by these results, we next examined the enantioselective intramolecular Tishchenko reaction of a meso-dialdehyde. With the utility of the product in mind, we selected the meso-aldehyde 10 as a model substrate (Scheme 3). The requisite aldehyde was prepared in 3 steps from cis-3-cyclobutene1,2-dimethanol 8. ${ }^{11}$ Protection of the diol with diphenyldiazomethane followed by dihydroxylation gave the anti-diol 9 in 58\% yield as the major isomer. The relative configuration of $\mathbf{9}$ was unambiguously determined by the crystalline sponge (CS) method..$^{12}$ Oxidative cleavage ${ }^{13}$ of 9 by silica gel-supported $\mathrm{NaIO}_{4}$ gave the desired meso-dialdehyde $\mathbf{1 0 .}$

With the meso-dialdehyde $\mathbf{1 0}$ in hand, we investigated the enantioselective intramolecular Tishchenko reaction using a chiral Ir complex. After screening the catalysts and reaction conditions, we were pleased to find that the enantioselective intramolecular Tishchenko reaction was realized for the first time. Thus, treatment of $\mathbf{1 0}$ with $\mathrm{Cp} * \operatorname{Ir}[(R, R)$-Tsdpen $]\left(\mathbf{5} \mathbf{b}^{\mathbf{*}^{\mathbf{1 4}}}\right.$ TsDPEN $=N$-( $p$-toluenesulfonyl $)$-1,2-diphenylethylenediamine $)$ (10 mol\%) and ${ }^{i} \mathrm{PrOH}(20 \mathrm{~mol} \%)$ in the presence of $\mathrm{K}_{2} \mathrm{CO}_{3}$ (40 mol\%) in $\mathrm{CH}_{2} \mathrm{Cl}_{2}$ at $30{ }^{\circ} \mathrm{C}$ for $24 \mathrm{~h}$ provided the desired $11 \mathrm{in}$

Table 1 Intramolecular Tishchenko reaction of aromatic dialdehydes ${ }^{a}$
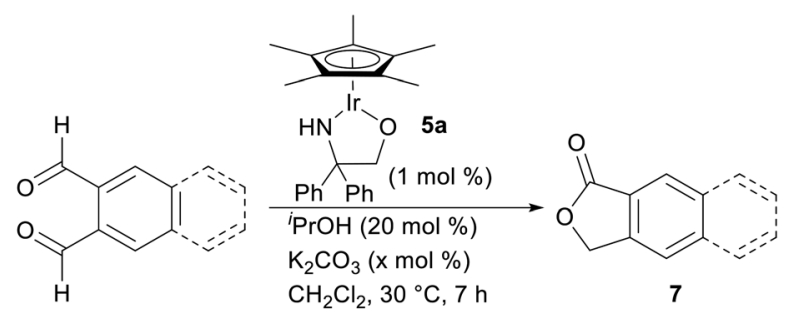

6a : o-phthalaldehyde

6b : naphthalene-2,3-dicarbaldehyde

\begin{tabular}{llllll}
\hline Entry & Aldehyde & $\mathrm{Ir}(\mathbf{5 a})$ & ${ }^{i} \mathrm{PrOH}$ & $\mathrm{K}_{2} \mathrm{CO}_{3}(x \mathrm{~mol} \%)$ & Yield (\%) \\
\hline 1 & $\mathbf{6 a}$ & + & + & 20 & 97 \\
2 & $\mathbf{6 a}$ & - & + & 20 & 0 \\
3 & $\mathbf{6 a}$ & + & - & 20 & 24 \\
4 & $\mathbf{6 a}$ & + & + & - & 6 \\
5 & 6a & + & + & 10 & 28 \\
6 & 6b & + & + & 20 & 97
\end{tabular}

${ }^{a}$ All the reactions were carried out on a $0.15 \mathrm{mmol}$ scale of 6 .

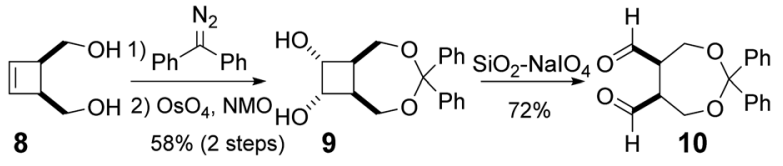

Scheme 3 Synthesis of meso-dialdehyde 10.

$83 \%$ yield with $78 \%$ ee (Table 2 , entry 1 ). The reaction in acetonitrile proceeded quantitatively, but the enantioselectivity was diminished (entry 2). The reaction in the presence of $\mathrm{K}_{3} \mathrm{PO}_{4}$ slightly increased the chemical yield and ee (entry 3). Finally, the addition of a phosphoric acid, ${ }^{15}(\mathrm{PhO})_{2} \mathrm{PO}_{2} \mathrm{H}$, increased the enantioselectivity ( $91 \%$ ee, entry 4 ). Similar positive effects of the phosphoric acid on the enantioselectivity were also observed with $10 \mathrm{~mol} \%$ of chiral phosphoric acids such as TRIP $\left(\right.$ TRIP $=3,3^{\prime}$-bis(2,4,6-triisopropylphenyl)-1,1'-binaphthyl-2,2'diylhydrogen phosphate). However $(R)$-TRIP and $(S)$-TRIP gave the same enantioselectivity.

The absolute configuration of $\mathbf{1 1}$ was unambiguously determined by single crystal X-ray crystallographic analysis using the optically pure lactone obtained by recrystallization (Fig. 1).

To compare the enantioselective intramolecular Tishchenko reaction with the enantioselective oxidative lactonization, ${ }^{6}$ the corresponding diol 12 was treated with the same catalyst in the presence of acetone as an oxidant, to afford the desired lactone 11 in $92 \%$ yield and $79 \%$ ee with $(5 \mathrm{a} S, 8 \mathrm{a} R)$ configuration (Scheme 4). The addition of (PhO $)_{2} \mathrm{PO}_{2} \mathrm{H}$ did not improve the enantioselectivity in this reaction system $(87 \%, 78 \%$ ee).

These results show that both enantiomers of the lactone can be prepared using the same catalyst by selecting the appropriate reaction system (Scheme 5). The enantioselective intramolecular Tishchenko reaction and the enantioselective

Table 2 Enantioselective intramolecular Tishchenko reaction of meso-dialdehyde $10^{a}$

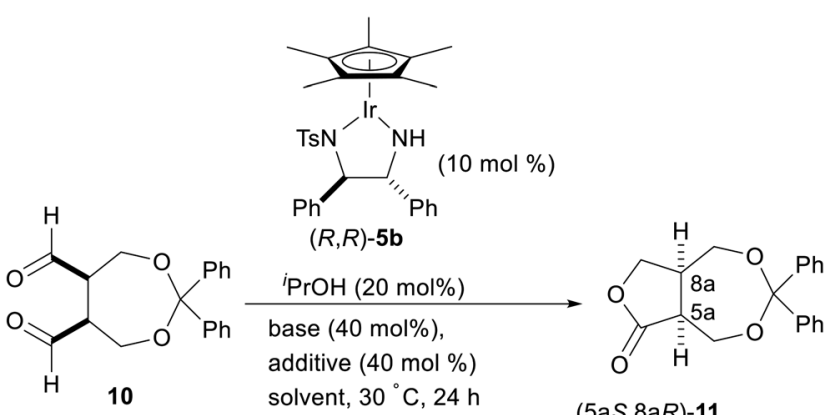

\begin{tabular}{|c|c|c|c|c|c|}
\hline Entry & Solvent & Base & Additive & Yield $^{b}(\%)$ & $\operatorname{Ee}^{c}(\%)$ \\
\hline 1 & $\mathrm{CH}_{2} \mathrm{Cl}_{2}$ & $\mathrm{~K}_{2} \mathrm{CO}_{3}$ & None & 83 & 78 \\
\hline 2 & $\mathrm{CH}_{3} \mathrm{CN}$ & $\mathrm{K}_{2} \mathrm{CO}_{3}$ & None & $>99$ & 68 \\
\hline 3 & $\mathrm{CH}_{2} \mathrm{Cl}_{2}$ & $\mathrm{~K}_{3} \mathrm{PO}_{4}$ & None & 87 & 80 \\
\hline 4 & $\mathrm{CH}_{2} \mathrm{Cl}_{2}$ & $\mathrm{~K}_{2} \mathrm{CO}_{3}$ & $(\mathrm{PhO})_{2} \mathrm{PO}_{2} \mathrm{H}$ & 78 & 91 \\
\hline
\end{tabular}




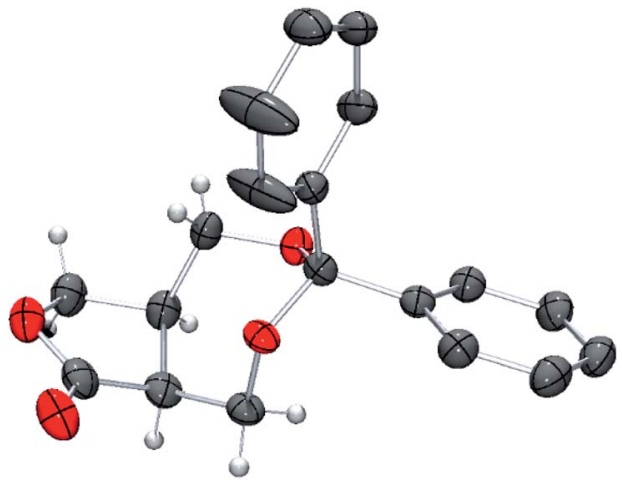

Fig. 1 POV-ray depiction of $(5 \mathrm{aS}, 8 \mathrm{a} R)$-11. Thermal ellipsoid is drawn at the $50 \%$ probability level. $H$ atoms on benzene rings are omitted for clarify.

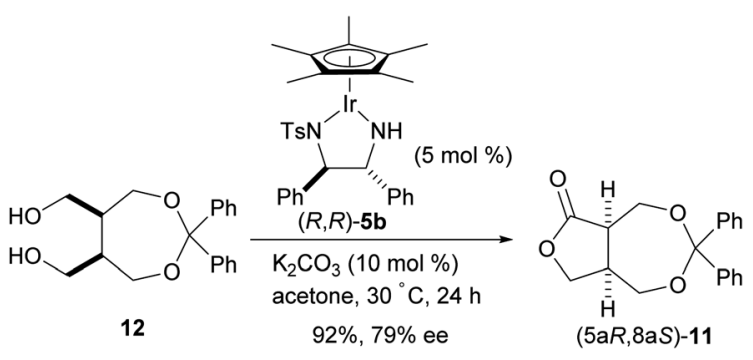

Scheme 4 Enantioselective oxidative lactonization of meso-diol 12.

asymmetric Tishchenko reaction

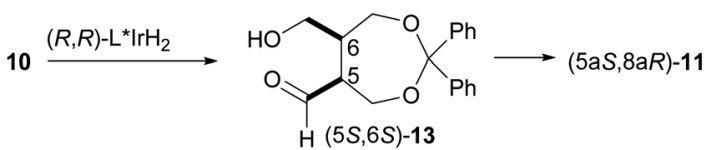

asymmetric oxidative lactonization

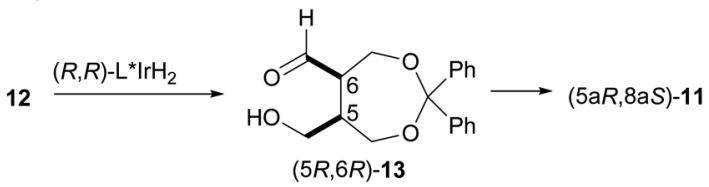<smiles>[R4]O[R4]#[X]</smiles>

Scheme 5 Comparison of enantioselective intramolecular Tishchenko reaction with enantioselective oxidative lactonization.

oxidative lactonization are complementary, indicating both reactions pass through the same transition state.

In this reaction, we used 16 electron Ir complex $\mathbf{5 b}$ and ${ }^{i} \mathrm{PrOH}$ to generate the 18 electron Ir hydride complex. To obtain information on the catalyst, cold spray ionization mass spectrometry (CSI-MS) ${ }^{16}$ was conducted. The sample prepared from 5b and iPrOH gave a prominent peak at $\mathrm{m} / \mathrm{z} 695$ corresponding to the 18 electron Ir hydride complex, $\mathrm{Cp} * \mathrm{IrH}$ $\left[\mathrm{TsNCHPhCHPhNH}_{2}\right]+\mathrm{H}^{+}$. The Ir complex formed from $\mathbf{5 b}$ and 1 equiv. of $(\mathrm{PhO})_{2} \mathrm{PO}_{2} \mathrm{H}$ in ${ }^{i} \mathrm{PrOH}$ exhibited a peak at $\mathrm{m} / z 965$ due to $\mathrm{Cp} * \operatorname{IrH}\left[\mathrm{TsNCHPhCHPhNH} \mathrm{H}_{2}\right]\left[\mathrm{OPO}(\mathrm{OPh})_{2}\right]+\mathrm{Na}^{+}$. These results indicate that $\mathrm{Cp} * \mathrm{Ir}$, TsDPEN, and phosphoric acid contribute to the formation of an efficient asymmetric environment. ${ }^{15}$

Having succeeded in the first intramolecular enantioselective Tishchenko reaction of meso-dialdehyde, we then applied our method to the synthesis of several natural products. Cedarmycins were isolated in 2001 by the Frumai and Igarashi groups from a plant called Cryptomeria japonica. ${ }^{17}$ Cedarmycins exhibit antibiotic activity with cedarmycin A showing potent activity against candida glabrata IFO 0622, comparable to amphotericin B. To date, two groups have reported different methods for the racemic synthesis of the cedarmycins. ${ }^{18}$ However, no reports on the catalytic asymmetric synthesis or the absolute configurations of these compounds have been published. As shown in Scheme 6, the deprotection of $\mathbf{1 1}$ under hydrogenolysis conditions afforded the desired cis-diol 14. Sequential double acylation/elimination of $\mathbf{1 4}$ proceeded in the presence of DBU to give cedarmycins A (15a) and B (15b) in 76\% and $85 \%$ yields, respectively. By comparison of their optical rotations, the absolute configurations of cedarmycins A and B were determined to be $(S)$. It should be noted that cleavage of the acetal moiety of $\mathbf{1 1}$ by acid hydrolysis caused partial racemization of $\mathbf{1 5}$. The racemization likely occurred by the recyclization of cis-14 by the nucleophilic attack of the $\gamma$-hydroxy group under acidic conditions.

In conclusion, we have achieved the first enantioselective intramolecular Tishchenko reaction of meso-dialdehydes and applied this methodology to the synthesis of natural products. Chiral lactones are useful chiral building block for the organic synthesis. The direct conversion of 1,4-dialdehydes to $\gamma$ lactones is attractive from the view point of environmentally benign redox neutral process. ${ }^{19}$ Additional studies on the substrate scope and reaction mechanism are currently in progress in our laboratory.

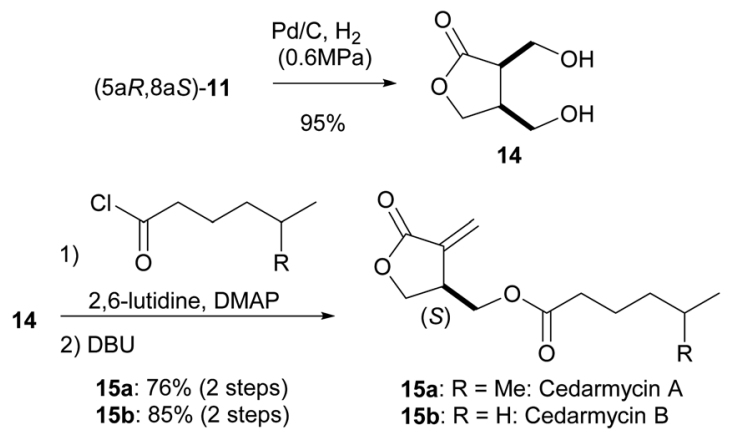

Scheme 6 Catalytic enantioselective synthesis of cedarmycins A and B. 


\section{Conflicts of interest}

There are no conflicts to declare.

\section{Acknowledgements}

This work was supported by JSPS KAKENHI (Grant No. 26410047, 17K05784, 20K05494) and Uehara Memorial Foundation. This work was also supported in part by "Dynamic Alliance for Open Innovation Bridging Human, Environment and Materials" in "Network Joint Research Center for Materials and Devices" (No. 20194015) from the Ministry of Education, Culture, Sports, Science and Technology of Japan (MEXT). We are also grateful to Tsuyoshi Matsuzaki, Hitoshi Haneoka, and Tsunayoshi Takehara of the Comprehensive Analysis Center of ISIR for their assistance.

\section{Notes and references}

1 L. Claisen, Ber. Dtsch. Chem. Ges., 1887, 20, 646-650.

2 W. Tischtschenko, J. Russ. Phys. Chem., 1906, 38, 355-418.

3 B. N. Pattanaik and H. C. Mandalia, Int. J. Curr. Res. Rev., 2011, 3, 23-40.

4 (a) O. P. Tormakangas and A. M. P. Koskinen, Recent Res. Dev. Org. Chem., 2001, 5, 225-255; (b) T. Seki, T. Nakajo and M. Onaka, Chem. Lett., 2006, 35, 824-829; (c) A. M. P. Koskinen and A. O. Kataja, in Organic Reactions, ed. S. E. Denmark, John Wiley \& Sons, Inc., Hoboken, 2015, vol. 86, pp. 105-410; (d) R. Dhanya, T. Shilpa, S. Saranya and G. Anilkumar, ChemistrySelect, 2020, 5, 754763.

5 (a) T. Suzuki, T. Yamada, T. Matsuo, K. Watanabe and T. Katoh, Synlett, 2005, 2005, 1450-1452; (b) T. Suzuki, T. Yamada, K. Watanabe and T. Katoh, Bioorg. Med. Chem. Lett., 2005, 15, 2583-2585.

6 T. Suzuki, K. Morita, Y. Matsuo and K. Hiroi, Tetrahedron Lett., 2003, 44, 2003-2006.

7 (a) Z. Shen, H. A. Khan and V. M. Dong, J. Am. Chem. Soc., 2008, 130, 2916-2917; (b) D. Hojo, K. Noguchi and K. Tanaka, Angew. Chem., Int. Ed., 2009, 48, 8129-8132; (c) D. H. Phan, B. Kim and V. M. Dong, J. Am. Chem. Soc., 2009, 131, 15608-15609; (d) Z. Shen, P. K. Dornan, H. A. Khan, T. K. Woo and V. M. Dong, J. Am. Chem. Soc., 2009, 131, 1077-1091; (e) M. C. Willis, Angew. Chem., Int. Ed., 2010, 49, 6026-6027; (f) H. A. Khan, K. G. M. Kou and V. M. Dong, Chem. Sci., 2011, 2, 407-410; (g) S. K. Murphy and V. M. Dong, J. Am. Chem. Soc., 2013, 135, 5553-5556; (h) L. Souillart and N. Cramer, Angew. Chem., Int. Ed., 2014, 53, 9640-9644; ( $i$ ) X. Wu, Z. Chen, Y. B. Bai and V. M. Dong, J. Am. Chem. Soc., 2016, 138, 12013-12016; (j)
T. Shirai, T. Iwasaki, K. Kanemoto and Y. Yamamoto, Chem.-Asian J., 2020, 15, 1858-1862.

8 (a) C. M. Mascarenhas, S. P. Miller, P. S. White and J. P. Morken, Angew. Chem., Int. Ed., 2001, 40, 601-603; (b) C. Schneider and M. Hansch, Synlett, 2003, 2003, 837-840; (c) V. Gnanadesikan, Y. Horiuchi, T. Ohshima and M. Shibasaki, J. Am. Chem. Soc., 2004, 126, 7782-7783; (d) J. Mlynarski and M. Mitura, Tetrahedron Lett., 2004, 45, 7549-7552; (e) Y. Horiuchi, V. Gnanadesikan, T. Ohshima, H. Masu, K. Katagiri, Y. Sei, K. Yamaguchi and M. Shibasaki, Chem. -Eur. J., 2005, 11, 5195-5204; $(f)$ J. Mlynarski, J. Jankowska and B. Rakiel, Chem. Commun., 2005, 4854-4856; (g) J. Mlynarski, J. Jankowska and B. Rakiel, Tetrahedron: Asymmetry, 2005, 16, 1521-1526; $(h)$ K. Rohr, R. Herre and R. Mahrwald, Org. Lett., 2005, 7, 4499-4501; ( $i$ ) M. Stodulski, J. Jazwinski and J. Mlynarski, Eur. J. Org. Chem., 2008, 2008, 5553-5562; (j) T. Asano, S. Kotani and M. Nakajima, Org. Lett., 2019, 21, 4192-4196.

9 (a) M. H. S. A. Hamid, P. A. Slatford and J. M. J. Williams, $A d v$. Synth. Catal., 2007, 349, 1555-1575; (b) T. Suzuki, Chem. Rev., 2011, 111, 1825-1845; (c) J. M. Ketcham, I. Shin, T. P. Montgomery and M. J. Krische, Angew. Chem., Int. Ed ., 2014, 53, 9142-9150; (d) T. Kwok, O. Hoff, R. J. Armstrong and T. J. Donohoe, Chem. -Eur. J., 2020, 26, 12912-12926.

10 T. Suzuki, K. Morita, M. Tsuchida and K. Hiroi, Org. Lett., 2002, 4, 2361-2363.

11 N. Gauvry, C. Comoy, C. Lescop and F. Huet, Synthesis, 1999, 1999, 574-576.

12 Y. Inokuma, S. Yoshioka, J. Ariyoshi, T. Arai, Y. Hitora, K. Takada, S. Matsunaga, K. Rissanen and M. Fujita, Nature, 2013, 495, 461-466.

13 Y. L. Zhong and T. K. Shing, J. Org. Chem., 1997, 62, 26222624.

14 K. Mashima, T. Abe and K. Tani, Chem. Lett., 1998, 12011202.

15 (a) C. Li, B. Villa-Marcos and J. Xiao, J. Am. Chem. Soc., 2009, 131, 6967-6969; (b) W. J. Tang and J. L. Xiao, Synthesis, 2014, 46, 1297-1302; (c) S. Tribedi, C. M. Hadad and R. B. Sunoj, Chem. Sci., 2018, 9, 6126-6133.

16 S. Sakamoto, M. Fujita, K. Kim and K. Yamaguchi, Tetrahedron, 2000, 56, 955-964.

17 T. Sasaki, Y. Igarashi, N. Saito and T. Furumai, J. Antibiot., 2001, 54, 567-572.

18 (a) H. S. Yang, X. X. Qiao, Q. Cui and X. H. Xu, Chin. Chem. Lett., 2009, 20, 1023-1024; (b) M. G. Lloyd, M. D'Acunto, R. J. K. Taylor and W. P. Unsworth, Tetrahedron, 2015, 71, 7107-7123.

19 S. H. Bergens, D. P. Fairlie and B. Bosnich, Organometallics, 1990, 9, 566-571. 